\title{
A INFLUÊNCIA DA PROMOÇÃO DE VENDAS NA CAPTAÇÃO DE CLIENTES: UM ESTUDO NA HOTELARIA CATARINENSE
}

\section{THE INFLUENCE OF SALES PROMOTION ON CUSTOMER ACQUISITION: A STUDY IN HOSPITALITY IN SANTA CATARINA STATE - BRAZIL}

\section{Tiago Savi Mondo}

Doutorando em Administração pela Universidade Federal de Santa Catarina - UFSC

Professor do Instituto Federal de Educação, Ciência e Tecnologia de Santa Catarina - IFSC.

E-mail: tiago.mondo@ifsc.edu.br (Brasil)

\section{Jane Iara Pereira da Costa}

Doutora em Engenharia de Produção pela Universidade Federal de Santa Catarina - UFSC

Professora da Universidade do Estado de Santa Catarina - UDESC

E-mail: costajane@udesc.br (Brasil) 


\title{
A INFLUÊNCIA DA PROMOÇÃO DE VENDAS NA CAPTAÇÃO DE CLIENTES: UM ESTUDO NA HOTELARIA CATARINENSE
}

\section{RESUMO}

As ações de comunicação de marketing implementadas pelas organizações, servem a propósitos diversos e muitas vezes, para atrair e captar clientes. A promoção de vendas, como ação do composto de comunicação destaca-se como uma ação de resultados de curto prazo e com grande eficácia. A partir destas considerações, o objetivo central deste estudo é analisar a influência da promoção de vendas na captação de clientes em meios de hospedagem $(\mathrm{MH})$ de Santa Catarina. O estudo se caracteriza como de natureza exploratória, descritiva caracterizando-se também como de abordagem qualitativa e quantitativa, do tipo estudo de campo. A amostra da etapa qualitativa foi composta por 13 meios de hospedagem e da etapa quantitativa por 52 elementos respondentes. Todos os meios de hospedagem pesquisados são vinculados à Associação Brasileira da Indústria hoteleira-SC. A pesquisa foi realizada de março a agosto de 2010. Os principais resultados indicam que a promoção de vendas é realizada na baixa temporada, com o foco de aumentar a ocupação, correspondendo ao que a teoria sugere - ações de curto prazo. Além disso, a ação foi considerada muito importante para a captação de clientes, pois se configura como a base para o aumento da ocupação, durantes períodos de baixa temporada.

Palavras-chave: Comunicação de marketing, promoção de vendas, hotelaria, Santa Catarina, captação de clientes.

\section{THE INFLUENCE OF SALES PROMOTION ON CUSTOMER ACQUISITION: A STUDY IN HOSPITALITY IN SANTA CATARINA STATE - BRAZIL}

\begin{abstract}
The actions of marketing communication implemented by organizations serve different purposes including attracting and capturing customers. Sales promotion, a form of communication, stands out as an effective short-term action. Based on these considerations, the main purpose of this study is to analyze the influence of sales promotion on hotels in Santa Catarina State - Brazil. The study is characterized as exploratory and descriptive, and utilizes both a qualitative and a quantitative approach. The qualitative phase consisted of data from 13 hotels and the quantitative phase consisted of respondents from 52 hotels. All hotels surveyed are linked to the Hospitality Industry Association-SC (ABIH-SC). The survey was conducted from March to August 2010. The main results indicate that sales promotion is primarily used during the least busy season (low season), with the focus on increasing occupancy, corresponding to what the theory suggests - short-term solutions. Moreover, the action was considered very important for attracting customers because it provides the basis for the increase in occupancy during the low season.
\end{abstract}

Keywords: marketing communication, sales promotion, hospitality, Santa Catarina, customer acquisition

REMark - Revista Brasileira de Marketing, São Paulo, v. 12, n. 2, p. 87-107, abr./jun. 2013. 


\section{INTRODUÇÃO}

O turismo é um dos principais atores da economia mundial, sendo o representante principal do setor de serviços. Dentro da ampla gama de elementos do setor turístico, os empreendimentos de hospedagem (hotéis, pousadas, resorts, etc.) têm papel fundamental para o desenvolvimento deste segmento.

Barreto (2007) menciona que a hotelaria nasceu como um elemento complementar do turismo. Na verdade, não se tem registro preciso de quando e como surgiu a atividade hoteleira no mundo. Entretanto, pode-se observar ao longo da história mundial que esta atividade possa ter surgido em função da necessidade natural que os viajantes tiveram e têm em procurar abrigo, apoio e alimentação durante suas viagens.

Corroborando o autor, Campos e Gonçalves (1998) defendem que os MH são fundamentais na viabilização da atividade turística e a falta deles pode fazer com que uma região com grande potencial turístico não se desenvolva.

Em função do crescimento do setor das viagens e turismo, o número de meios de hospedagens também aumentou e em função da globalização e da concorrência acirrada do setor os meios de hospedagens se viram diante do desafio de criar e desenvolver produtos e serviços visando captar e manter a lealdade de seus clientes. É neste sentido que aparece o destacado "produto ampliado" de Kotler (2006).

No contexto global atual da economia de mercado aberto, o consumidor tornou-se rei. Ele opera através de seu poder autônomo, possui liberdade em sua decisão de compra e está em posição de influenciar o fabricante ou o comerciante quanto à qualidade, tamanho e conteúdo do produto, preço e serviço de pós-venda, entre outras coisas. (Das e Kumar, 2009). Captar um cliente se torna função primordial do setor de marketing das empresas.

A partir disso, captar clientes para usufruírem dos serviços oferecidos pelo hotel assume papel relevante para a manutenção e o desenvolvimento do empreendimento hoteleiro. O setor responsável para promover o estudo e a relação do hotel com o seu mercado deve ser o setor de marketing (Kotler, 2000).

Autores clássicos da área de marketing de serviços como Lovelock e Wirtz (2006-), Zeithaml e Bitner (2003) e Grönroos (2004) mencionam que o setor de comunicação de marketing é o mais importante na captação de clientes, seguido do setor de distribuição.

Dentre as ações de comunicação de marketing, a promoção de vendas é considerada uma das mais importantes, principalmente para alavancar a captação de clientes. A promoção de vendas é a comunicação ligada a um incentivo. São geralmente específicas a um período de tempo, preço ou grupo de clientes. O objetivo é acelerar a decisão de compra, captar o cliente ou fazer com que ele

REMark - Revista Brasileira de Marketing, São Paulo, v. 12, n. 2, p. 87-107, abr./jun. 2013. 
compre em maior quantidade. As amostras, cupons, descontos, brindes e concursos são alguns dos exemplos deste item do mix de comunicação de marketing (Lovelock e Wirtz, 2006).

A promoção de vendas pode ser interativa com o consumidor, no caso de concursos, campanhas, sorteios, entre outros (Lupetti, 2007).

As estratégias ligadas à promoção de vendas têm como objetivos esvaziar estoque, impulsionar a venda de um produto ou serviço que está em baixa, promover a marca, captar clientes entre outros (Lovelock e Wirtz, 2006).

Isto posto, a pergunta que norteia a realização deste estudo é: Qual a influência da promoção de vendas na captação de clientes em meios de hospedagem de Santa Catarina?

Para responder ao questionamento, formulou-se o objetivo do estudo, a saber: analisar a influência da promoção de vendas na captação de clientes em MH de Santa Catarina.

O Estado de Santa Catarina foi escolhido como foco do estudo por ser considerado um dos principais receptores de turistas no Brasil, sendo reconhecido especialmente em razão das belezas naturais do seu litoral, concentrando-se na alta estação a maior demanda turística de lazer. De acordo com SANTUR (2012) o movimento de turistas nos meses de verão em Santa Catarina no ano de 2010 ultrapassou os sete milhões gerando um fluxo de aproximadamente 4 bilhões de reais no período.

Possui duas cidades entre os 10 principais destinos de lazer do país (Florianópolis e Balneário Comburiu (MTUR, 2011), além de Florianópolis ser a terceira colocada em destinos de turismo de eventos.

Assim, a relevância do presente estudo está em, a partir deste contexto de crescimento do turismo no Estado, analisar de que forma a promoção de vendas influência na captação de clientes em meios de hospedagem.

\section{FUNDAMENTAÇÃO TEÓRICA}

Para situar o tema desta investigação, é necessário, inicialmente, apresentar a base teórica sobre a qual se assenta o desenvolvimento da pesquisa realizada. A partir disso, a comunicação de marketing e a ação de promoção de vendas são exploradas a seguir.

REMark - Revista Brasileira de Marketing, São Paulo, v. 12, n. 2, p. 87-107, abr./jun. 2013. 


\section{COMUNICAÇÃO DE MARKETING}

Mangols e Faulds (2009) definem comunicações de marketing integrado (IMC) como sendo o princípio orientador que as organizações seguem para se comunicar com seus mercados-alvo, coordenando e controlando os diversos elementos do mix promocional, publicidade, venda pessoal, relações públicas, marketing direto e promoção de vendas - para produzir foco na mensagem e, portanto, atingir os objetivos organizacionais traçados.

As ferramentas de comunicação de marketing são importantes nos serviços e ajudam a criar imagens poderosas e um sentido de credibilidade, confiança e tranqüilidade. Sem uma comunicação eficaz, clientes potenciais talvez nem tomem conhecimento da existência de uma empresa de serviços, daquilo que ela tem para lhes oferecer ou de como utilizar seus produtos para obter o melhor proveito (Lovelock e Wirtz, 2006).

Os principais objetivos da comunicação de marketing são o de tornar a organização e seus serviços conhecidos e atraentes para público potencial e manter os consumidores fiéis bem informados sobre a realidade da empresa (Amaral, 2008).

Outras definições sobre a comunicação de marketing são encontradas na literatura, contudo, todas muito parecidas. Grönroos (2004) menciona que as comunicações integradas de marketing podem ser definidas como estratégias que integram o marketing tradicional, marketing direto, relações públicas e outros meios distintos de comunicações de marketing, bem como os aspectos de comunicação da entrega e do consumo de serviços, do atendimento ao cliente e outros encontros com o cliente.

Além da divulgação da empresa e do relacionamento, Lovelock e Wirtz (2006) acreditam que a comunicação de marketing também é utilizada para persuadir clientes-alvo, mostrando que a oferta é a melhor disponível para satisfazer a necessidade do cliente potencial.

Corroborando a relação do marketing com a captação e retenção de clientes, Candido e Viera (2003) defendem que o entendimento do comportamento dos clientes e a criação de um canal de comunicações do prestador de serviço com esse cliente é uma das ações que o marketing executa.

Almeida (2008) discute em seu trabalho os objetivos da comunicação de marketing na hotelaria e acredita que se o objetivo da comunicação é aumentar a divulgação do estabelecimento hoteleiro, o programa de comunicação deve utilizar-se de um plano de meios ou veículos de elevada cobertura.

Para trabalhar questões tão diversificadas e entender o processo de comunicação de marketing é necessário conhecer suas ferramentas e possibilidades de utilização profundamente. Assim, Lovelock e Wirtz (2006) definem o mix de comunicação de marketing como o composto de

REMark - Revista Brasileira de Marketing, São Paulo, v. 12, n. 2, p. 87-107, abr./jun. 2013. 
comunicações pessoais, propaganda, promoção de vendas, publicidade e relações públicas, materiais de instrução e projeto corporativo.

Neste estudo, o foco de ação dentre os componentes do mix de comunicação será a promoção de vendas, apresentado no tópico seguinte.

\section{PROMOÇÃO DE VENDAS}

Grande parte da promoção de vendas é focada em promover um impacto imediato. $\mathrm{O}$ objetivo é fazer com que a compra aconteça imediatamente, oferecendo um incentivo para estimular o consumo. Exemplos de tais incentivos incluem amostras grátis de produtos, cupons, os descontos (oferta de reembolso em dinheiro), prêmios (algum item desejável que vem com um item que está sendo vendido), publicidade (uma caneca de café com o nome do anunciante, por exemplo), a recompensa de compra ou programas de fidelidade, ponto em promoções, concursos, sorteios e jogos. Os consumidores individuais não são o único foco das promoções de vendas, pois elas também podem ser projetadas para clientes comerciais, varejistas e atacadistas e membros da força de vendas. (Wendy e Oppenheim, 2004)

Dessa forma, Kotler e Armstrong $(2001,559)$ conceituam a promoção de vendas como "os incentivos de curto prazo para encorajar a compra ou venda de um produto ou serviço". Rao (2009) ainda menciona que os profissionais de marketing estão cada vez mais contando com as táticas de curto prazo, tais como promoções de vendas para atingir seus objetivos.

A maioria das ofertas promocionais são oferecidas com o único critério de influenciar a compra imediata. Os produtos vendidos em ofertas promocionais têm um maior valor percebido quando comparado com produtos regularmente vendidos e, como tal, a hipótese de influenciar as intenções de compra do cliente. Estudos realizados por Grewal et al (1991) e Dodds et al (1991) foram capazes de estabelecer essa relação.

Complementando a ideia, Rao (2009) menciona que a promoção de vendas propicia um incentivo extra ao consumidor para que o mesmo faça a compra imediata do produto ou serviço. Um exemplo empírico é o estudo de Liao, Shen e Chu (2009) que identificaram que uma promoção de vendas com recompensa instantânea promove maior influência na compra do que uma promoção com recompensa atrasada. Tal fato indica que o desconto (dado na hora da venda da diária) e o upgrade de categoria disponibilizado no momento em que o cliente faz o check-in ou até mesmo no momento da compra antecipada influenciam a percepção do mesmo com relação à compra.

A recompensa imediata inerente a atividades de promoção de vendas não é diferente do conceito de compra por impulso, na medida em que envolve também a espontaneidade, a falta de

REMark - Revista Brasileira de Marketing, São Paulo, v. 12, n. 2, p. 87-107, abr./jun. 2013. 
reflexão, o imediatismo e cinética para incentivar o comportamento de compra dos consumidores impulsivos (Rook e Hoch, 1985).

Assim, no planejamento de promoções de vendas, o preço tornou-se uma variável importante. A influência do preço é uma conseqüência do fato de que, no mínimo ele representa o que os consumidores vão ter que sacrificar a fim de realizar uma compra. Negativamente falando, preços mais altos afetam as probabilidades de compra, ou seja, os consumidores gostariam de se abster de comprar produtos com altos preços, por isso a elaboração dos descontos. (Lichtenstein et al, 1993).

Carl e Lawrence (1999) mencionam que as promoções de vendas visam aumentar a sensibilidade dos preços no consumidor, mas nota que, sob algumas condições, tais promoções podem ser rentáveis tanto para varejistas como para fabricantes.

Apesar de ter previsto que as promoções de vendas têm um efeito positivo sobre o conhecimento da marca, este efeito pode depender do tipo de promoção. Laurent e Chandon (1999) e Chandon et al (2000) salientam a necessidade de distinguir entre dois tipos, monetárias e não monetárias, porque há diferenças importantes entre eles.

Por um lado, as promoções monetárias (por exemplo, produtos grátis, cupons) são principalmente relacionados a benefícios utilitários, que têm uma natureza instrumental, funcional e cognitiva. Eles ajudam os consumidores a aumentar a utilidade da aquisição da sua compra e aumentar a eficácia da sua experiência de compra. Por outro lado, as promoções não monetárias (concursos, sorteios, brindes, programas de fidelidade) estão relacionadas a benefícios hedônicos com um carácter instrumental, vivencial e afetivo, porque são intrinsecamente gratificantes e relacionados com emoções experiencial, prazer e auto-estima.

De acordo com Ferracciu (2002) as promoções de vendas monetárias são atividades que objetivam resultados de curto prazo nas vendas, questão corroborada por Lancaster (2009). Outra função é apresentada por Moi (2006) e Crescitelli (2007) que mencionam que as promoções voltadas ao preço servem para o encorajamento de troca da marca.

Por outro lado, as promoções não monetárias são utilizadas em ações de longo prazo, com promoção da imagem da marca e proposta de novos mercados e novos produtos. (Aaker, 1991; Pizzinatto, 2008).

Shimp (2003) defende que as técnicas de promoção de vendas, sejam monetárias ou não, recompensam o cliente com algum incentivo ou estímulo, encorajando-o a compra. $\mathrm{O}$ autor complementa que a redução de preço (desconto) deve ser utilizada quando o gestor pensa em recompensar os usuários da marca, levar os consumidores a comprar mais, deter a concorrência, obter diversos espaços e fornecer incentivos aos varejistas. Kumar e Swaminathan (2005) defendem

REMark - Revista Brasileira de Marketing, São Paulo, v. 12, n. 2, p. 87-107, abr./jun. 2013. 
que quanto maior o percentual de desconto, maior a influência que esse tipo de promoção causa nas compras.

O cupom pode ser considerado um item bem conhecido da promoção de vendas. Configura como mecanismo promocional que oferece algum desconto ao consumidor no momento em que é apresentado. Burns (2009) identificou que 99\% dos consumidores norte-americados já usaram algum tipo de cupom e que a avaliação de bom ou muito bom foi de 93\%. Shimp (2003) menciona que no Canadá e na Europa os cupons são também muito utilizados ao passo que no Brasil este tipo de promoção de vendas é pouco utilizado.

Outra ação de promoção de vendas são os bônus. Shimp (2003) indica que compreende em quantidade extra de produto ou serviço que a empresa oferece aos consumidores pelo preço regular. No caso dos produtos é chamado de bônus de embalagem e no caso dos serviços, bônus de serviço.

Algumas promoções recompensam os consumidores por suas compras repetidas, fornecendo pontos que vão sendo acumulados e posteriormente, ao final da promoção ou ao atingir uma certa quantidade são somados podendo ser convertidos em descontos no preço, em produtos grátis, ou em pontos para aquisição de produtos ou serviços. (Pinheiro, 2010).

Os concursos ou sorteios oferecem aos consumidores oportunidades de ganhar dinheiro, viagens, serviços ou outros produtos. Muitas vezes utilizados para melhorar a imagem da empresa. A ação de comunicação de marketing de propaganda é utilizada em conjunto com esse tipo de promoção de vendas (Burns, 2009).

Vidal e Delgado-Ballester (2005) consideraram que as promoções de vendas, que compoem as comunicações de marketing, têm um efeito a nível cognitivo e emocional, e fornecem ao consumidor múltiplos benefícios hedônicos e utilitários. Os autores verificaram em seu estudo se as promoções de vendas podem contribuir para a construção de brand equity. Concluiram que as promoções monetária e não-monetária são úteis para criar brand equity devido ao seu efeito positivo sobre as estruturas de conhecimento da marca, sendo as promoções não-monetárias as maiores influenciadoras do brand equity.

Das e Kumar (2009) identificaram em seu estudo que é positivo o impacto das promoções de vendas no comportamento do consumidor no varejo da Índia. Moschis, Curasi e Bellenger (2004) verificaram que os consumidores mais velhos são muito conscientes do preço, com uma memória, muitas vezes exigente para os preços dos itens comprados frequentemente fazendo com que as empresas tenham que se utilizar do uso freqüente de promoções de redução de preços.

REMark - Revista Brasileira de Marketing, São Paulo, v. 12, n. 2, p. 87-107, abr./jun. 2013. 


\section{METODOLOGIA}

Esta pesquisa, de cunho exploratório possui abordagem qualitativa e quantitativa. As abordagens foram combinadas a fim de dar maior fidedignidade aos resultados e profundidade nas análises. A primeira etapa empírica desta pesquisa foi a de abordagem qualitativa. Esta, segundo Godoi e Balsini (2006) abrange diversas formas de pesquisa e auxilia o pesquisador a compreender e explicar o fenômeno social imerso no ambiente

Esta etapa de cunho exploratório caracterizou-se pela abordagem pessoal dos gestores dos $\mathrm{MH}$ pertencentes à amostra. Esta etapa se caracteriza pela realização de entrevistas em profundidade com os gestores comerciais dos empreendimentos hoteleiros da amostra escolhida.

O procedimento utilizado para a escolha da amostra na fase qualitativa foi o nãoprobabilístico. A amostragem é por acessibilidade ou conveniência. Segundo Gil (2002) o pesquisador seleciona os elementos a que tem acesso, admitindo que estes possam, de alguma forma, representar o universo.

Todos os hotéis da pesquisa pertencem à Associação Brasileira da Indústria Hoteleira ABIH-SC. Os hotéis escolhidos para a amostra nos diferentes segmentos são apresentados a seguir:

- Turismo de Lazer - Três Resorts, duas Pousadas, dois Hotéis de Lazer e três hotéis de Aguas Termais. Turismo de Negócios $\rightarrow$ Dois Hotéis Turismo Rural: Um Hotel

A amostra compreendeu $13 \mathrm{MH}$ para a etapa qualitativa e exploratória do estudo, situados em nove municípios catarinenses, como demonstra a figura 1. Foram pesquisados hotéis com relevância de mercado nas regiões. Os hotéis estão enquadrados nas principais regiões turísticas do estado de Santa Catarina.

REMark - Revista Brasileira de Marketing, São Paulo, v. 12, n. 2, p. 87-107, abr./jun. 2013. 
Figura 1 - Mapa amostral da etapa qualitativa.

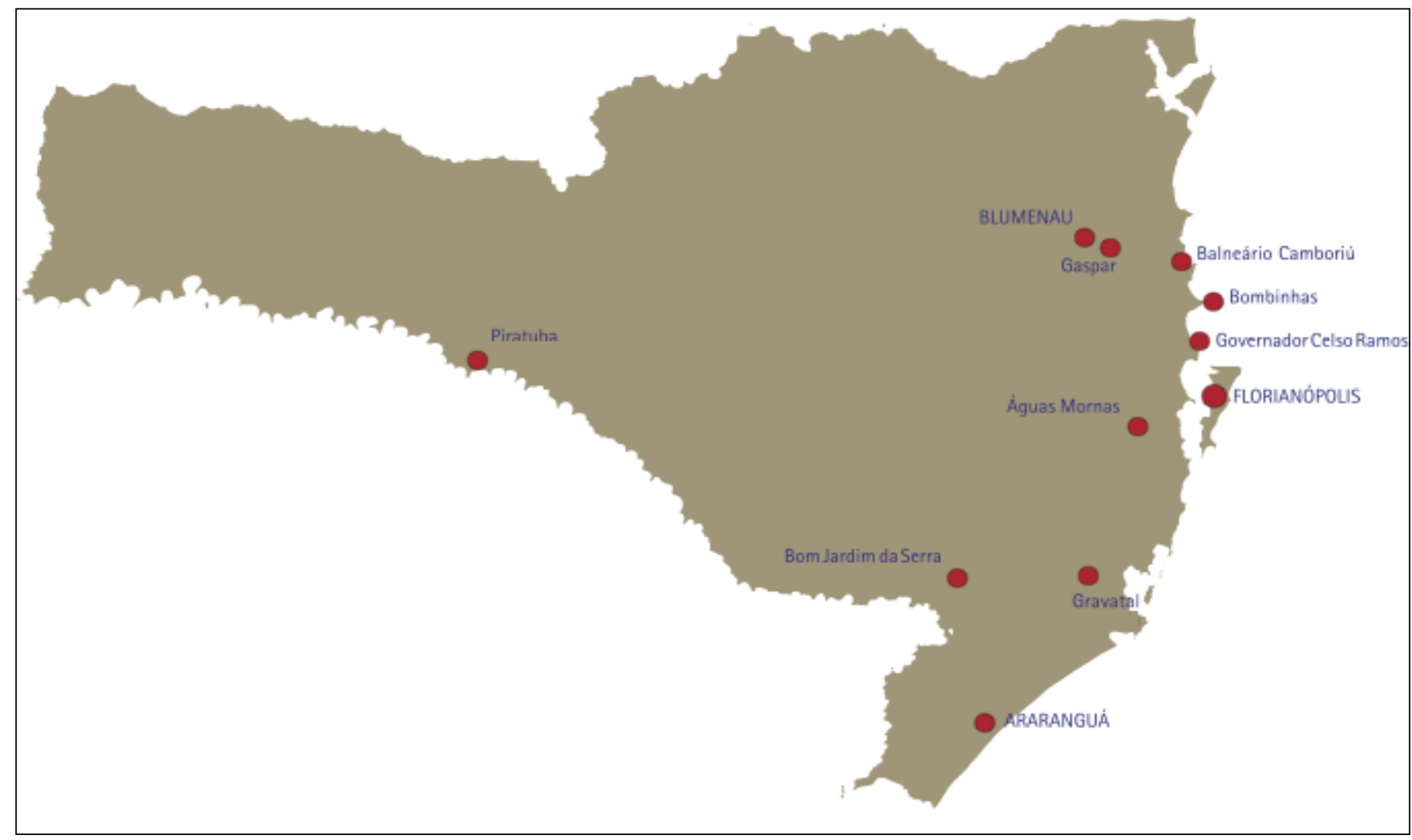

Fonte: Dados primários /2010

O instrumento utilizado na etapa qualitativa desta pesquisa foi entrevista em profundidade. De acordo com Godoi e Mattos (2006) o estilo aberto desta prática permite a obtenção de uma riqueza informativa, proporciona a clarificação de temas e respostas e na fase inicial de uma pesquisa é importante, pois gera pontos de vista, enfoques, hipóteses e outras orientações úteis para serem desenvolvidas no decorrer da pesquisa.

A coleta de dados foi realizada em reuniões previamente agendadas com os gestores gerais ou gestores comerciais dos $\mathrm{MH}$ da amostra. Teve duração média de 40 minutos por entrevista e todas foram realizadas nas dependências dos próprios MH. Os dados foram gravados digitalmente e transcritos para posterior análise.

Neste estudo, após a transcrição das entrevistas, foi realizada uma fase de análise da narrativa do entrevistado, após isso se criaram fatores e categorias de análise. A próxima etapa foi confrontar tais fatores e categorias com a fundamentação teórica existente, buscando relação e confrontações e chegando-se a uma análise com maior aprofundamento.

Por último, com base nas narrativas e na identificação de fatores ou categorias de análise decorrentes da narrativa foi realizado um "resumo analítico" dos principais pontos levantados. 


\section{PESQUISA QUANTITATIVA}

Após a realização da pesquisa qualitativa, foi realizada a etapa da pesquisa de abordagem quantitativa. A pesquisa quantitativa é denominada também de pesquisa de levantamento (Creswell, 2007). Tem por característica principal a descrição quantitativa ou numérica de tendências, atitudes ou opiniões de uma população. Assim, se enquadra no objetivo deste estudo. Após a pesquisa exploratória da etapa qualitativa, a pesquisa quantitativa focalizou uma amostra da população para juntamente com os dados qualitativos dar base para as análises e conclusões do estudo.

A etapa quantitativa deste estudo classifica-se como descritiva. Segundo Gil (2002) as pesquisas descritivas têm como objetivo central a descrição das características de determinada população ou fenômeno ou o estabelecimento de relações entre variáveis. Ainda segundo o autor, algumas pesquisas descritivas vão além da simples identificação da existência de relações entre variáveis e objetivam determinar a natureza dessas relações.

Esta etapa da pesquisa caracteriza-se por ser do tipo de levantamento ou survey. Segundo May (2004) as surveys oferecem uma maneira rápida e barata de descobrir as características e crenças da população.

O questionário online foi o instrumento utilizado para a coleta de dados na etapa quantitativa do estudo. Ficou disponível para preenchimento durante $1 \mathrm{mÊs}$,

Os emails de contato para convite aos gestores foram disponibilizados pela ABIH-SC. O link do questionário online foi o HTTP://hotelariasc.questionpro.com.

Das 102 visitas que ocorreram no link do site, 10 visitas foram repetidas, ou seja, o mesmo empreendimento visitou mais de uma vez. Tal fato resulta que $92 \mathrm{MH}$ visitaram efetivamente o link do questionário. Destes, 52 iniciaram o preenchimento e 40 preencheram-no por completo.

O percentual de respostas do questionário perante sua população foi de $29,44 \%$ e o de questionários válidos foi de $22,22 \%$. As respostas obtidas são consideradas satisfatórias visto que outros estudos que possuem coleta de dados mediante instrumento online obtiveram participações inferiores à desta pesquisa. Exemplo disso é o estudo de Abreu e Costa (2008) que obteve percentual de resposta de $7,6 \%$.

Outras abordagens empíricas utilizando a Internet como veículo de comunicação, como a de Fontenot \& Vlosk (1998) e Vieira, Viana \& Echeveste (1998) apud Abreu e Costa (2008), apresentam taxas inferiores a 5,5\%, o que indica que o número obtido é satisfatório.

Assim, considera-se que o número de $52 \mathrm{MH}$, dos 180 possíveis é tido como significante para que, conjuntamente com os $13 \mathrm{MH}$ da etapa qualitativa seja possível realizar as análises necessárias relativas ao tema central desse estudo.

REMark - Revista Brasileira de Marketing, São Paulo, v. 12, n. 2, p. 87-107, abr./jun. 2013. 
O mapa amostral da etapa quantitativa é apresentado na Figura 2. Identifica-se que foram pesquisados $\mathrm{MH}$ pertencentes às 10 regiões turísticas do Estado de Santa Catarina. Para a análise dos dados quantitativos foram utilizadas técnicas de estatística descritiva como médias, desviopadrão, freqüência e tabelas cruzadas. Além disso, foi realizado teste paramétrico de $t$ de student para comparação de médias.

Figura 2 - Mapa amostral da etapa quantitativa

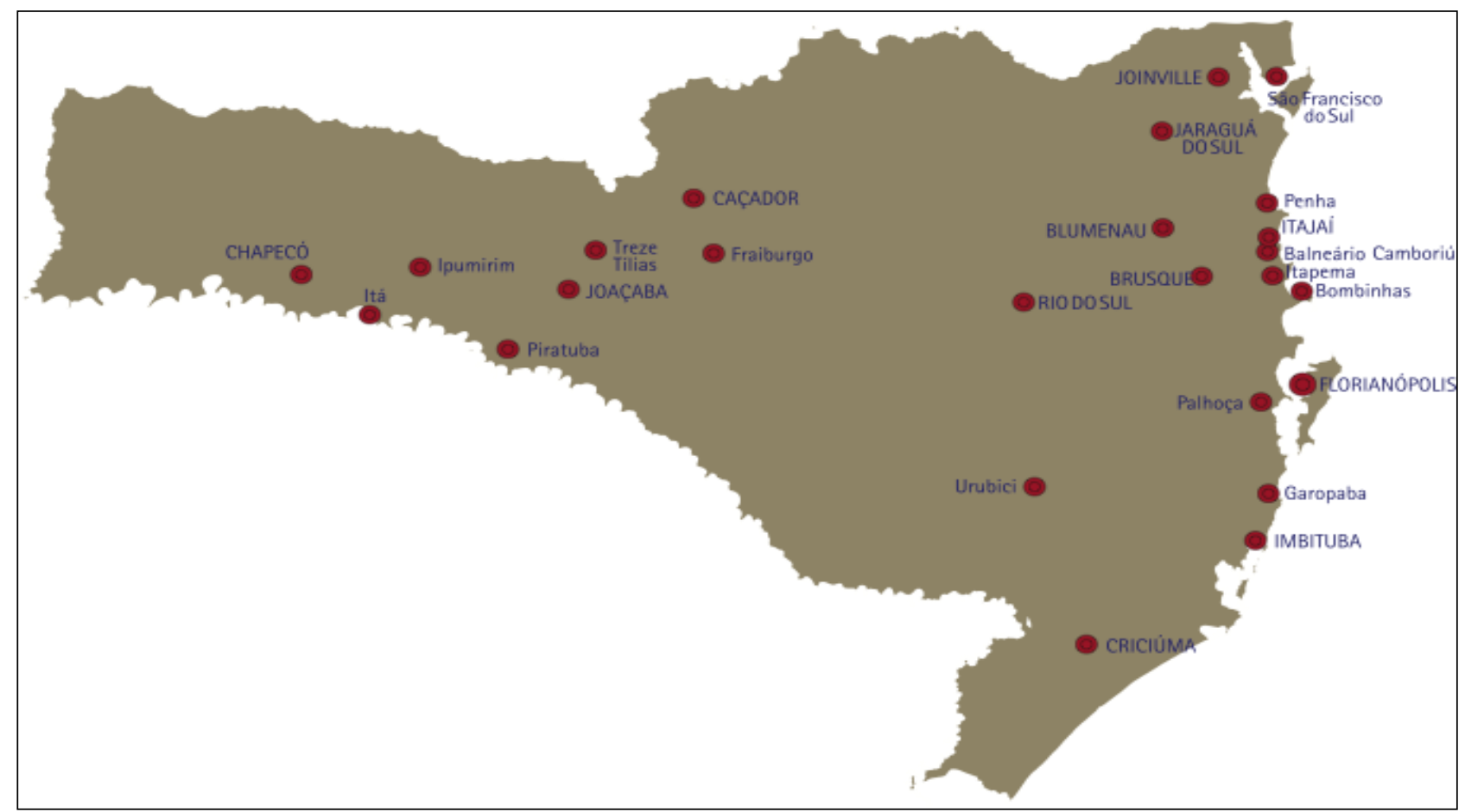

Fonte: dados primários / 2010.

\section{RESULTADOS}

A seguir são apresentados os achados da pesquisa, relacionados com os objetivos delineados.

A promoção de vendas é uma das ações de comunicação de marketing mais utilizadas pelas empresas de diferentes segmentos. No turismo, devido à sazonalidade, uma das alternativas para tentar reverter a baixa ocupação é a formulação de promoção de vendas, como demonstrado nos depoimentos dos gestores a seguir, principalmente no Estado de Santa Catarina, onde o turismo de lazer/verão é evidente e, no inverno, a ocupação nos meios de hospedagem possuem grande queda.

\footnotetext{
"A gente realiza mais na baixa temporada, na alta temporada a gente já tem um público fiel ao nosso hotel, que sempre vem todo ano, então por sermos um hotel de praia, que não tem tantas opções no período de inverno, a gente realiza promoções, inclusive no site você pode dar uma olhada que vai ter lá todas as promoções que a gente vai ter (Gestor do Hotel de Praia-MH -1)".
}

REMark - Revista Brasileira de Marketing, São Paulo, v. 12, n. 2, p. 87-107, abr./jun. 2013. 
"A gente tem muitas promoções, inclusive mais promoções na baixa temporada do que na alta, obviamente, mas o lazer em Florianópolis ainda é pequeno na baixa temporada, então na verdade a gente mesmo tendo muitas promoções não consegue atingir o objetivo que gostaríamos (Gestora Hotel de Praia - MH2)".

"Tu vem acompanhando uma linha de crescimento na área comercial e em alguns períodos, principalmente em Florianópolis que a sazonalidade é grande e em um período longo, então a gente segmenta algumas promoções pro público catarinense, algum feriado, dentro de um calendário, de um feriado de uma cidade próxima, então tem um desconto especial, ou alguma atração especial na formatação do pacote (Resort de Praia - MH-3)".

A importância da promoção de vendas é corroborada por dados de ocupação em meios de hospedagem no estado. De acordo com a ABIH (2011) a média anual estadual de ocupação ficou em torno de $45 \%$. Nos pacotes de Reveillon esta média passa para $85 \%$ e nos pacotes de Carnaval para aproximadamente $70 \%$.

Percebe-se que o segmento da demanda chega a modificar devido à sazonalidade. Outra questão destacada pelos gestores foi trabalhar a promoção de vendas na baixa temporada, em feriados, datas festivas e períodos em que existe maior disponibilidade de UH's no meio de hospedagem.

\begin{abstract}
"A gente trabalha com várias tarifas. Nosso mês de baixa temporada é junho, exceto no feriado, primeira quinzena de julho e agosto, esses são os períodos onde o hotel faz maior desconto. E todo feriado prolongado é pacote, cujo valor é maior. E também trabalhamos com desconto de acordo com o mapa né, mapa de disponibilidade (Hotel de Aguas Termais $-\mathrm{MH}-4) "$
\end{abstract}

Outra alternativa de promoção de vendas identificada na pesquisa qualitativa foi sua utilização em fins de semana, especialmente em hotéis de negócios, onde tem seus picos de ocupação durantes os dias de semana.

"Fazemos promoção para os finais de semana Desconto de diária e dá muito upgrade de categoria, isso tudo aumenta muito a ocupação (Hotel Executivo - MH-5)”.

O ponto de vista contrário é o da Pousada MH-6, que tem sua baixa ocupação durante a semana e, a partir disso, foca suas promoções de venda neste período, para público específico. “A gente tá criando algum pacote nesse sentido pra representantes, porque a nossa semana não é legal e estamos sobrevivendo na baixa temporada basicamente de representantes comerciais na semana".

Outro ponto que merece destaque é a influência que o mercado provoca nas promoções de vendas. O Resort MH-7 teve que repensar sua estratégia de marketing devido à crise mundial de 2008/2009.

\footnotetext{
“A gente não trabalha com promoções, não trabalhava, nunca fizemos, também por motivos de imagem, porém, a gente tá percebendo agora, do ano passado pra esse ano, que tá uma época muito diferente com a crise mundial, no nosso segmento, o segmento de luxo, então tu vai pra um hotel excelente na Europa, e eles tão fazendo promoções muito baratas, e a mesma coisa nos Estados Unidos e em outros países, e aqui no Brasil não, não estavam fazendo, esse ano começaram, e a gente teve que ir atrás (Resort - MH-7)".
}

REMark - Revista Brasileira de Marketing, São Paulo, v. 12, n. 2, p. 87-107, abr./jun. 2013. 
Destaca-se também a utilização da promoção como forma de relacionamento com o cliente final. Apesar de ser um apelo para venda e para captação, a promoção de vendas pode se transformar em estratégia de relacionamento.

"É fundamental criar, construir uma forma, dessas promoções de venda, cada promoção tem um objetivo, seja pra fidelizar o cliente, seja pra fazer realmente uma captação, pra fazer um relacionamento, pra cada um a gente percebe que tem um retorno, se não, não estaríamos perdendo dinheiro e tempo pra isso né (Hotel Executivo - MH8)".

Além dos tipos convencionais de promoção de vendas, identificaram-se duas novas formas de promoção de vendas em MH: a promoção last minute e a promoção de benefício de diárias.

\begin{abstract}
"A gente trabalha muito com promoção de last minute, como tem as companhias aéreas, então a gente, de repente tem um volume de vendas bom, pra determinado período de feriado ou pra determinada semana, a gente lança no site, e por e-mail marketing uma promoção de last minute, com um percentual de desconto, é bem comum, a gente faz, e é promoção por tempo limitado e número de apartamentos limitados, então a gente controla isso e quando chega naquele limite que a gente estabelece, fechou a promoção (Hotel de Praia - MH2)".
\end{abstract}

"Geralmente a partir de sete dias a gente oferece três dias "free", em baixa temporada ou dez dias, dois dias "free”, a gente faz uns pacotes bem legais (Pousada - MH9)."

O gestor comercial do Hotel de Águas Termais - MH10 destaca algumas limitações da promoção de vendas. Argumenta que é preciso que as promoções de vendas abranjam todas as UH's e todos os clientes, pois no segmento de lazer, onde os hóspedes se conhecem com maior frequiência é difícil vender o hotel de formas diferentes, pois pode causar constrangimento ao hóspede.

\footnotetext{
"Então tens que fazer uma coisa, tens que inserir todo mundo, então fazes uma promoção, que manda lá newsletter, dizendo que hóspedes que ficar aqui, no mínimo duas permanências, ganham $10 \%$ de desconto, isso dá bastante retorno também. Só que tu tens que abranger todos os clientes. (Hotel de Aguar termais - MH-10)”.
}

Dessa forma, percebe-se que a promoção de vendas é um dos mecanismos mais utilizados para o objetivo principal de captação. Possui suas limitações, mas ao mesmo tempo, apresenta várias possibilidades para sua utilização, que podem ser adotadas por todos os $\mathrm{MH}$, independente de tamanho, segmento ou público-alvo. Sempre, é claro, de acordo com as estratégias de marketing do empreendimento.

Na pesquisa quantitativa, $80 \%$ dos $\mathrm{MH}$ da amostra costumam realizar promoção de vendas. Além disso, o índice de importância da promoção de vendas para captação foi de 3,80 (mínimo 1 e máximo 5). A tabela 1 apresenta as freqüências de resposta dos gestores com relação à importância da promoção de vendas para a captação.

REMark - Revista Brasileira de Marketing, São Paulo, v. 12, n. 2, p. 87-107, abr./jun. 2013. 
Tabela 1 - Importância da Promoção de Vendas para Captação de Clientes

\begin{tabular}{|c|l|c|c|c|c|}
\hline \multicolumn{2}{|c|}{} & FREQUÊNCIA & PERCENTUAL & $\begin{array}{c}\text { PERCENTUAL } \\
\text { VÁLD. }\end{array}$ & $\begin{array}{c}\text { PERCENTUAL } \\
\text { AC. }\end{array}$ \\
\hline \multirow{4}{*}{$\begin{array}{c}\text { Dados } \\
\text { Válidos }\end{array}$} & Pouca Importância & 1 & 1,9 & 2,5 & 2,5 \\
\cline { 2 - 6 } & Média Importância & 12 & 23,1 & 30,0 & 32,5 \\
\cline { 2 - 6 } & Muita Importância & 21 & 40,4 & 52,5 & 85,0 \\
\cline { 2 - 6 } & Máxima Importância & 6 & 11,5 & 15,0 & 100,0 \\
\cline { 2 - 6 } & Total & 40 & 76,9 & 100,0 & \\
\hline
\end{tabular}

Fonte: dados primários/2010.

Percebe-se através da tabela que mais da metade dos gestores $(52,5 \%)$ consideram muito importante a promoção de vendas para a captação de clientes, mostrando que sua influência é positiva. Neste ponto é possível afirmar que existe concordância entre os dados qualitativos e quantitativos coletados.

Os tipos mais utilizados de promoção de vendas nos MH são os descontos nas diárias (87,5\% dos MH que realizam promoção de vendas), seguidos dos pacotes promocionais $(65,63 \%)$, upgrades de categoria $(31,25 \%)$, brindes $(28,13 \%)$ e por último os bônus $(18,75 \%)$ como demonstrados no Gráfico 1.

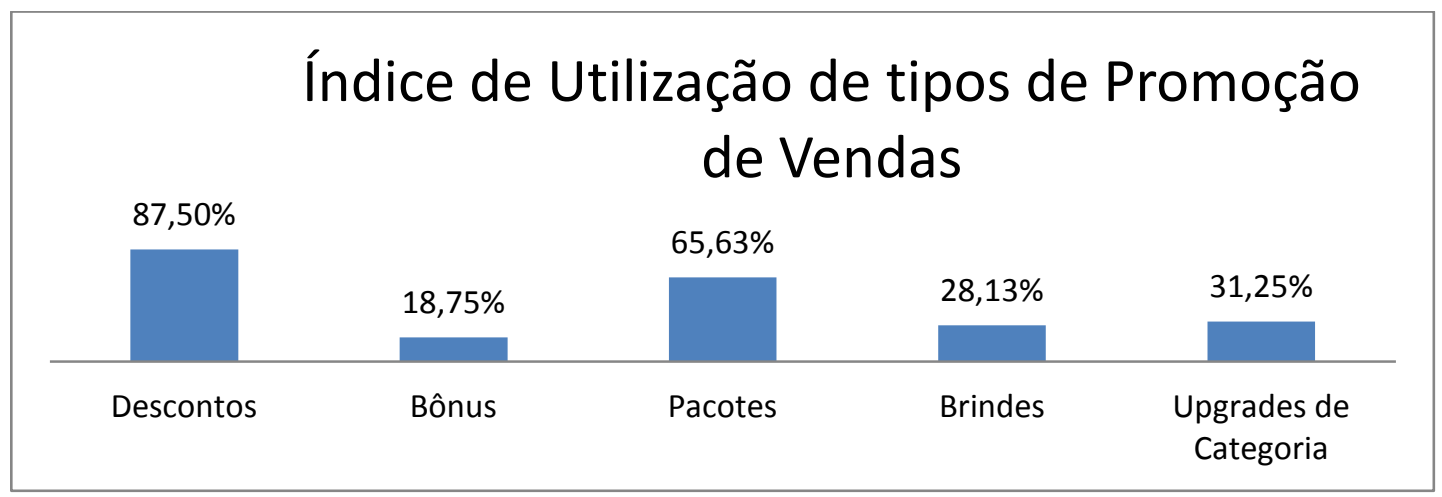

Gráfico 1 - Índices de Utilização de tipos de Promoção de Vendas Fonte: dados primários/ 2010.

Percebe-se a utilização predominante de promoções classificadas como monetárias segundo Laurent e Chandon (1999) e Chandon et al (2000) ajudando os consumidores a aumentar a utilidade da aquisição da sua compra e aumentar a eficácia da sua experiência de compra. São pouco utilizadas as promoções não monetárias resultando em uma menor preocupação dos gestores com os benefícios hedônicos, vivenciais e afetivos, ligados à experiência e a marca do hotel.

Buscou-se identificar além do exposto, a utilização da promoção de vendas de acordo com a classificação dos MH. Os resultados são apresentados na tabela 2.

REMark - Revista Brasileira de Marketing, São Paulo, v. 12, n. 2, p. 87-107, abr./jun. 2013. 
Tabela 2 - Realização de promoção de Vendas x Classificação MH

\begin{tabular}{|l|c|c|c|c|c|}
\hline \multicolumn{2}{|c|}{} & \multicolumn{3}{|c|}{ PORTE } & \multirow{2}{*}{ TOTAL } \\
\cline { 3 - 6 } Realização de Promoção de Vendas & POUSADA & HOTEL & RESORT & \\
\cline { 2 - 6 } & Não & 0 & 7 & 1 & 8 \\
\cline { 2 - 6 } & Sim & 11 & 19 & 2 & 32 \\
\hline TOTAL & 11 & 26 & 3 & 40 \\
\hline
\end{tabular}

Fonte: dados primários/2010.

Destaca-se neste ponto, a não utilização de promoção de vendas por sete dos 26 hotéis da amostra e a utilização desta ferramenta de comunicação por todas as pousadas. Apesar do teste de qui-quadrado não ter evidenciado índice de significância estatística, 0,145 , verifica-se esta pequena diferença, indicando que as pousadas utilizam com maior freqüência a promoção de vendas. Tal fato é corroborado pela análise da tabela 3, que apresenta as percepções de importância.

Tabela 3 - Importância da Promoção de Vendas x Classificação Meio de Hospedagem

\begin{tabular}{|c|l|c|c|c|c|}
\hline \multicolumn{2}{|c|}{} & \multicolumn{3}{|c|}{ PORTE } & \multirow{2}{*}{ TOTAL } \\
\cline { 3 - 5 } & POUSADA & HOTEL & RESORT & \\
\hline \multirow{4}{*}{$\begin{array}{c}\text { Importância Promoção de } \\
\text { Vendas }\end{array}$} & Pouca Importância & 0 & 1 & 0 & 1 \\
\cline { 2 - 6 } & Média Importância & 3 & 9 & 0 & 12 \\
\cline { 2 - 6 } & Muita Importância & 8 & 11 & 2 & 21 \\
\cline { 2 - 6 } & Máxima Importância & 0 & 5 & 1 & 6 \\
\hline \multicolumn{2}{|c|}{ TOTAL } & 11 & 26 & 3 & 40 \\
\hline
\end{tabular}

Fonte: dados primários/2010.

Os gestores das pousadas percebem com maior importância a promoção de vendas para captação de clientes, motivo este que pode ser considerado como principal influenciador na utilização destas promoções nas pousadas.

Uma hipótese explicativa desta questão pode ser a dificuldade que as pousadas têm, principalmente em baixa temporada, de efetivar suas vendas. Normalmente, os hotéis dos grandes destinos do Estado (Florianópolis, Balneário Camboriu, Blumenau, Joinville, etc) possuem demanda na baixa temporada em razão do Turismo de Eventos e de Negócios, como evidenciado na pesquisa da SANTUR (2012) que mostrou baixa sazonalidade em destinos de eventos e negócios no Estado. A preocupação em aumentar ocupação através de promoção de vendas pode ter sido um dos motivos que tenha levado aos resultados aqui apresentados.

Assim, com base na pesquisa qualitativa e na quantitativa foi possível perceber que a promoção de vendas destaca-se como ação indicada para captação de clientes em situações desfavoráveis e com baixa ocupação como em fins de semana para hotéis executivos, dias de semana para hotéis de lazer e em estações climáticas como o inverno em hotéis do litoral entre outras situações.

REMark - Revista Brasileira de Marketing, São Paulo, v. 12, n. 2, p. 87-107, abr./jun. 2013. 


\section{CONCLUSÃO}

O mercado de serviços turísticos no Brasil e, mais especificamente em Santa Catarina, tem crescido de forma expressiva, tanto em número de turistas (demanda), quando em oferta de atrativos, destinos e equipamentos turísticos (meios de hospedagem, agências, restaurantes). Estar alinhado a esse crescimento e ofertar serviços de qualidade deveria ser pressuposto básico para qualquer equipamento turístico.

Os MH configuram-se como o principal equipamento da atividade turística. Com o aumento da demanda, infere-se que a importância das modalidades de captação de clientes que os $\mathrm{MH}$ adotam deva aumentar em freqüência e em formas.

Com este artigo, buscou-se analisar a influência da promoção de vendas na captação de clientes em MH de Santa Catarina. Os gestores dos MH pesquisados, principalmente na etapa da pesquisa qualitativa, mostraram conhecer sua demanda potencial e, planejar dentro do possível, ações de promoção de vendas para atingir tal público.

A promoção de vendas é a ação de comunicação mais utilizada pelos $\mathrm{MH}$ pesquisados na baixa temporada, justamente, por ter resultados de curto prazo, objetivo central dos empreendimentos nos meses em que a ocupação está baixa, seguindo as definições de Kotler e Armstrong $(2001,559)$ que mencionam que deva se utilizar "os incentivos de curto prazo para encorajar a compra ou venda de um produto ou serviço

Outra questão verificada foi a predominância dos descontos. Como verificado na teoria, as promoções monetárias surtem maior efeito no comportamento do consumidor e promovem a compra com maior facilidade, diferentemente das promoções não monetárias que buscam benefícios hedônicos e valorização da marca.

Os pacotes de ação promocional característica do setor turístico, também obteve destaque de utilização, principalmente em fins de semana comemorativos e feriados.

A partir do exposto, é possível responder a pergunta de pesquisa, identificando que a promoção de vendas exerce forte influência na captação de clientes de MH de Santa Catarina, principalmente em baixa temporada.

Portanto, verifica-se que a promoção de vendas atua como uma ação estratégica da área comercial/marketing nos meios de hospedagem catarinenses. Entretanto, salienta-se que existe uma gama de possibilidades ainda não aplicadas. Tal fato deve instigar pesquisadores e profissionais da área de marketing de meios de hospedagem a estudarem e aplicarem novas técnicas de promoção de vendas, visando à diminuição da sazonalidade e o consequente aumento da ocupação.

O foco aqui se vira para a baixa temporada, pois na alta temporada não é necessário promover vendas, a demanda supera a oferta e não se tem problemas com a venda e a captação

REMark - Revista Brasileira de Marketing, São Paulo, v. 12, n. 2, p. 87-107, abr./jun. 2013. 
propriamente dita. Desse modo, a baixa temporada deve ser o foco de análise e aplicação das promoções de vendas.

Outro ponto inquietante na pesquisa foi a predominância de promoções monetárias. O turismo, cada vez mais, oferta experiência, dessa forma as promoções de vendas não monetárias poderiam ser melhor exploradas com o intuito de proporcionar benefícios hedônicos aos clientes, visando não somente benefícios melhor mensurados, mas questões mais subjetivas de comportamento frente à marca do meio de hospedagem.

Como sugestões de novos estudos sobre o tema, levanta-se a possibilidade de verificar a efetividade das diferentes tipologias de promoção de vendas e sua influência na captação de clientes, na perspectiva de gestores e hóspedes. Além disso, comparar com maior embasamento quantitativo, as ações de um maior número de $\mathrm{MH}$, divididos em tipologias características. 


\section{REFERÊNCIAS}

Aaker, D.(1991) Managing Brand Equity. New York: The Free Press.

Abreu, N.R.; Costa, E.B. (2010) "Estudo da viabilidade da utilização de marketing na internet no setor hoteleiro de Maceió". Disponível em: http://fama2.us.es:8080/turismo/turismonet1/economia\%20del\%20turismo/hosteleria/estudo\% 20de\%20viabilidade\%20do\%20utiliza\%E7ao\%20de\%20marketing\%20em\%20internet\%20no \%20sector\%20hoteleiro\%20Brazil.pdf. Acesso em: 20/04/2010.

Almeida, N. M. (2008) Uma avaliação de comunicação de Marketing na Hotelaria. Curso de Gestão. Universidade de Lisboa - Portugal, 2008. (Tese de Doutorado).

Amaral, S. A. (2008) "Marketing da informação: entre a promoção e a comunicação integrada de marketing”. In: Informação e Sociedade. v. 18, n.1, 31-44.

Barreto, A. I. (2007) As Contribuições Das Relações Públicas Para A Comunicação Mercadológica Hoteleira : A Rede Plaza De Hotéis, Resorts \& Spas Brasil. Curso de Comunicação Social. PUC-RS. (Monografia de Graduação).

Burns, E. (2009) Active Home Web Use by Country, January, 2009. Disponível em: http://www.com.clickbz.com. Acesso em:14 de Abril de 2009.

Campos, L.C; Gonçalves, M.H. (1998) Introdução ao Turismo e Hotelaria. RJ: Senac.

Candido,I.;Vieira, E. (2003) Gestão de Hotéis:técnicas, operações e serviços.Caxias: Educs.

Carl, F M; Laurence, M. (1999)“The Dynamic Effects of Discounting on Sales: Empirical Analysis and Normative Pricing Implications". Marketing Science, 18 (3), 317-332.

Chandon, P.; Wansink, B.; Gilles, L. (2000) "A benefit congruency framework of sales promotion effectiveness" In: Journal of Marketing, vol. 64, p. 65-81.

Crescistelli, E.; Ogden, J.(2007) Comunicação integrada de marketing: conceitos, técnicas e práticas. São Paulo: Pearson Prentice Hall.

Creswell, J. (2007) Projeto de pesquisa: métodos quali, quanti e misto. POA: Bookman.

Das, G.; Kumar, R.V. (2009) "Impact Of Sales Promotion On Buyers Behaviour: An Empirical Study Of Indian Retail Customers”. In: Globsyn Management Journal, 3 (1).

Dodds, W.M; Kent, B.; Grewal, D. (1991) "Effects of Price, Brand and Store Information on Buyer's Product Evaluations" In: Journal of Marketing Research, 28, 307-319.

Ferraciu, J. (2002) Marketing Promocional. São Paulo: Pearson Education do Brasil.

REMark - Revista Brasileira de Marketing, São Paulo, v. 12, n. 2, p. 87-107, abr./jun. 2013. 
Gil Ac. (2002) Como elaborar projetos de pesquisa. São Paulo (SP): Atlas.

Godoi, C. K.; Mattos, P. L. C. L. de. (2006) "Entrevista qualitativa: instrumento de pesquisa e evento dialógico". In: GODOI, C. K.; MELO, R. B. de; BARBOSA, A. Pesquisa Qualitativa em Estudos Org. - Paradigmas, Estratégias e Métodos. São Paulo: Saraiva.

Godoi, C; Balsini, C. (2006) "A pesquisa qualitativa nos estudos organizacionais brasileiros: uma análise bibliométrica". In: SILVA, A. et al (orgs) Pesquisa qualitativa em estudos organizacionais. São Paulo: Saraiva, 2006.

Grönroos, C. (2004) Marketing: gerenciamento e serviços. Rio de Janeiro: Elsevier.

Kotler, P.; Armstrong, G. (2001) Princípios de Marketing. São Paulo: Prentice Hall.

Kotler, Philip. (2000) Administração de Marketing. 10 ed. São Paulo: Prentice Hall. .(2006) Administração de marketing. 12. ed. São Paulo: Prentice-Hall.

Kumar, V.; Swaminathan, G. (2005) Marketing Research. New York: Wiley \& Sons.

Lancaster, G. (2009) Eventos e promoções de vendas. In: Shopping Center: Marketing. New York: ICSC.

Laurent G.; Chandon, P. (1999) "Hedonic and utilitarian consumer benefits of sales promotions." Marketing Science Institute Working Paper No. 99- 109.

Liao, S.L; Shen, Y.C.; Chu, C.H. (2009) "The effects of sales promotion strategy, product appeal and consumer traits on reminder impulse buying behavior." In: International Journal of Consumer Studies. 33, 274-284. doi: 10.1111/j.1470-6431.2009.00770.x

Lichtenstein, D.; Ridgway, N.; Netemeyer, R.G. (1993) "Price Perceptions and Consumer Shopping Behavior: A field Study". In: Journal of Marketing Research, 30, 234-45.

Lovelock, C.; Wirtz, L. (2006) Serviços: marketing e gestão. São Paulo: Saraiva.

Lupetti, M. (2007) Gestão estratégica da comunicação mercadológica. SP: T. Learning.

Mangols, Wg; Faulds, DJ. (2009) "Social media: The new hybrid element of the promotion mix". In: Business Horizons. v.52, n.4, 357-365.

May, Tim. (2004) Pesquisa social: questões, métodos e processos. POA: Artmed.

Moi, C.T. (2006) "Awareness and usage of promotional toy by Malasyan: the case of low involvement products.” In: Management Research News. 29, pp. 28-49.

REMark - Revista Brasileira de Marketing, São Paulo, v. 12, n. 2, p. 87-107, abr./jun. 2013. 
Moschis G, Curasi C, Bellenger, D. (2004) "Patronage motives of mature consumers in the selection of food...”. In: Journal of Consumer Marketing, 21(2), 123- 133.

Pinheiro, M. (2010) "Promoções de Venda em Shopping Center Comunitário: uma análise do faturamento das lojas satélites”. Dissertação (Mestrado). Universidade de Fortaleza, 2010.

Pizzinatto, A.; Pizzinatto, N.; Pizzinatto, N. "Marketing interno e cultura organizacional". In: Revista de Administração Mackenzie, 2008.

Rao, V. (2009) "Effect of Sales Promotions on Consumer Preferences - The Moderating Role of Price Perceptions and Deal Proneness". In: Journal of Management.

Rook, D.W; Hoch, S.J. (1985) “Consuming impulses”. Advances in Consumer Research, 12, 23-27.

Shimp, T. A. (2003) Comunicação Integrada de Marketing em Publicidade e Promoção. Thompson Learming.

Vidal, M. P.; Ballester, E.D. (2005) "Sales promotions effects on consumer based brand equity". In: International Journal of Market Research. 47 (2). Pp.179-204.

Wendy, Diamond, Oppenheim, M. (2004) Marketing Information: A Strategic Guide for Business and Finance Libraries. Binghamton, NY: Haworth Information Press.

Zeithaml, Valerie; BITNER, Mary J. (2003) Marketing de serviços: a empresa com foco no cliente. Porto Alegre: Bookman.

Data do recebimento do artigo: 03/01/2013

Data do aceite de publicação: 05/04/2013

REMark - Revista Brasileira de Marketing, São Paulo, v. 12, n. 2, p. 87-107, abr./jun. 2013. 